\title{
First report of autochthonous transmission of Zika virus in Brazil
}

\author{
Camila Zanluca', Vanessa Campos Andrade de Melo², Ana Luiza Pamplona Mosimann', \\ Glauco Igor Viana dos Santos ${ }^{2}$, Claudia Nunes Duarte dos Santos ${ }^{1 /+}$, Kleber Luz ${ }^{3 /+}$ \\ ${ }^{1}$ Laboratório de Virologia Molecular, Instituto Carlos Chagas, Fundação Oswaldo Cruz, Curitiba, PR, Brasil \\ ${ }^{2}$ Secretaria Estadual de Saúde do Rio Grande do Norte, Natal, RN, Brasil \\ ${ }^{3}$ Instituto de Medicina Tropical, Universidade Federal do Rio Grande do Norte, Natal, RN, Brasil
}

In the early 2015, several cases of patients presenting symptoms of mild fever, rash, conjunctivitis and arthralgia were reported in the northeastern Brazil. Although all patients lived in a dengue endemic area, molecular and serological diagnosis for dengue resulted negative. Chikungunya virus infection was also discarded. Subsequently, Zika virus (ZIKV) was detected by reverse transcription-polymerase chain reaction from the sera of eight patients and the result was confirmed by DNA sequencing. Phylogenetic analysis suggests that the ZIKV identified belongs to the Asian clade. This is the first report of ZIKV infection in Brazil.

Key words: Zika virus - “dengue-like syndrome” - Brazil

Zika virus (ZIKV) is an emerging arthropod borne virus (arbovirus) transmitted by Aedes (Stegomyia) mosquitoes. The virus belongs to the genus Flavivirus, family Flaviviridae, and is closely related to other flaviviruses of public health relevance including dengue (DENV), yellow fever and West Nile viruses (Pierson \& Diamond 2013, Faye et al. 2014).

ZIKV was first isolated from a rhesus monkey in the Zika Forest of Uganda, in 1947 (Dick et al. 1952). For half a century, the virus was described as causing sporadic human infections in Africa and Asia, until 2007 when a Zika fever epidemics took place in Yap Island, Micronesia (Duffy et al. 2009). In 2013, a large epidemic was reported in French Polynesia, concomitant with a dengue epidemic caused by serotypes 1 and 3. ZIKV has been considered as emergent since 2007 (Cao-Lormeau et al. 2014, Ioos et al. 2014).

In the early 2015 , records of patients presenting a "dengue-like syndrome" appeared in the public health service in the city of Natal $\left(05^{\circ} 47^{\prime} 42^{\prime \prime} \mathrm{S} 35^{\circ} 12^{\prime} 32^{\prime \prime O}\right)$, state of Rio Grande do Norte, Brazil. A physician specialist in infectious disease evaluated the patients and the clinical signs and symptoms and laboratory findings indicated a non-DENV and non-Chikungunya virus (CHIKV) infection. Symptoms included arthralgia, oedema of extremities, mild fever, maculopapular rashes frequently pruritic, headaches, retroorbital pain, no purulent conjunctivitis, vertigo, myalgia and digestive disorder.

By March 2015, the Molecular Virology Laboratory of Carlos Chagas Institute, Oswaldo Cruz Institute,

doi: $10.1590 / 0074-02760150192$

Financial support: FIOCRUZ, CNPq, CAPES, Fundação Araucária +Corresponding authors: clsantos@fiocruz.br, klebergluz@gmail.com Received 17 May 2015

Accepted 25 May 2015 state of Paraná, Brazil, received 21 acute-phase serum specimens from those patients exhibiting the "denguelike syndrome". Sera were transported and kept at $-80^{\circ} \mathrm{C}$ until use. The protocol was approved by the Brazilian Ethical Committee (42481115.7.0000.5248).

After RNA extraction, reverse transcription-polymerase chain reaction (RT-PCR) was performed as a rapid molecular tool to detect viral infection in acute-phase samples. Viral RNA was extracted from $140 \mu \mathrm{L}$ of sera by using QIAamp viral RNA mini kit (Qiagen, USA) according to the manufacturer's instructions.

The sera were first tested for DENV by RT-PCR (Lanciotti et al. 1992), ELISA for non-structural protein 1 antigen detection (Dengue Early ELISA, PanBio) and anti-DENV IgM (Dengue IgM Capture ELISA, PanBio), all yielded negative results. Moreover, all samples rendered negative results in RT-PCR assays for CHIKV infection (Lanciotti et al. 2007).

Since clinical symptoms were compatible with ZIKV infection, RT-PCR assay to specifically detect ZIKV RNA was performed, as described by Faye et al. (2008), with the modification that, instead of a one step, a two step protocol was used (cDNA synthesis followed by the PCR).

Amplicons of 364 bp encompassing the envelope protein coding region were obtained for eight out of 21 samples (Fig. 1). Two of the resultant amplicons were purified with High Pure PCR Purification kit (Roche) and sequenced in an ABI 3500 Genetic Analyzer (Applied Biosystems). Sequences were assembled using the Assembler tool (hpa-bioinformatics.org.uk/cgi-bin/ assembly_tool/seq_assemble.cgi?no=2) (GenBank accessions KR815989 and KR815990) and their identity were confirmed by Basic Local Alignment Search Tool (BLAST) and compared to other ZIKV sequences. Results demonstrated a high identity with sequences from the ZIKV Asian lineage. Despite the similarity of the clinical findings, the remaining samples resulted negative in RT-PCR, probably due to the short (and low) viraemia period (between the 3rd and 5th day after the onset of clinical symptoms). 

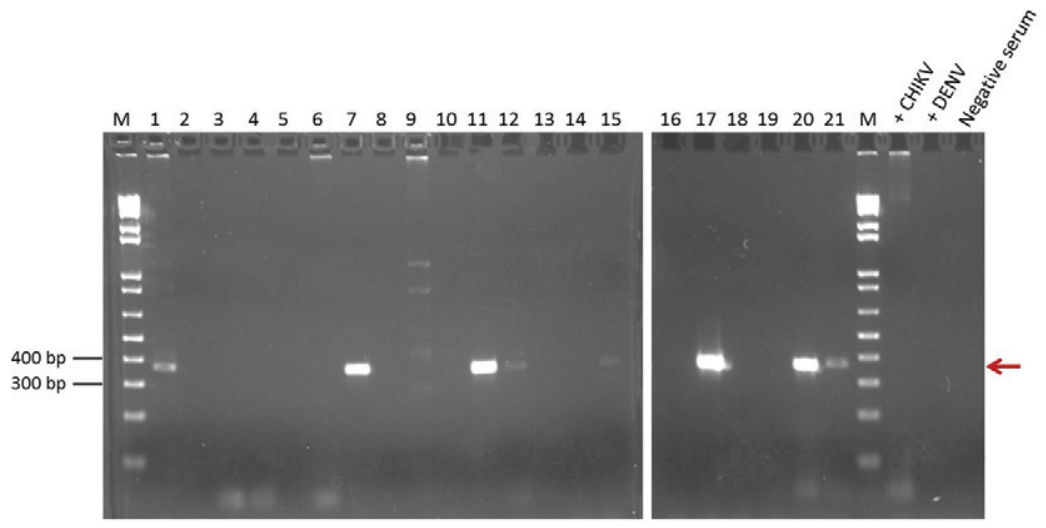

Fig. 1: agarose gel electrophoresis of reverse transcription-polymerase chain reaction assays for Zika virus (ZIKV) detection. The arrow indicates the $364 \mathrm{bp}$ amplicon expected for ZIKV. RNA extracted from serum samples of patients in acute-phase of dengue fever and Chikungunya fever and a negative serum sample were included as negative controls. CHIKV: Chikungunya virus; M: molecular size marker; 1-21: serum samples.

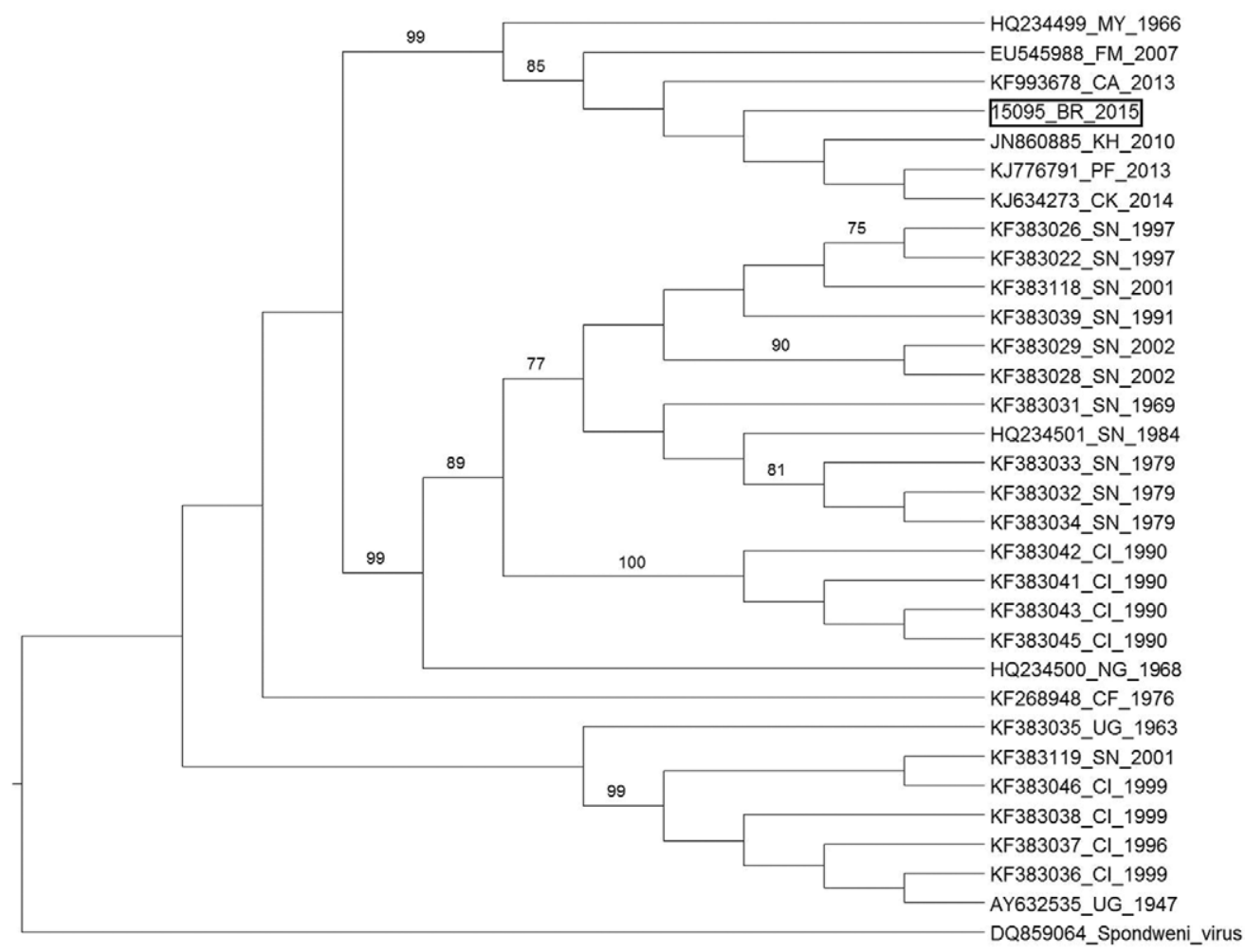

Fig. 2: phylogenetic analysis based on partial $E$ gene nucleic acid sequence (nt 1655-1984 according to AY632535) of a 2015 Brazilian strain of Zika virus. The tree was inferred using the maximum likelihood algorithm based on the Kimura two-parameter model with invariant sites as implemented in MEGA 6.05. The numbers shown to the left of the nodes represent bootstrap support values $>70$ (1,000 replicates). The tree was rooted with Spondoweni virus and branch lengths do not represent genetic distance. Strains were labelled according to GenBank accession /country 2-letter acronym/year of isolation.

Phylogenetic analysis of the sequences (Fig. 2) placed the Brazilian strains in a clade with sequences from the Asian lineage. The highest identity scores in BLAST were observed with the H/PF/2013 (99\%, GenBank accession KJ776791), CK-ISL 2014 (99\%, GenBank accession KJ634273) and FSS13025 (99\%, GenBank accession JN860885) isolates. The two generated sequences were identical between themselves in the region that was analysed (Fig. 2) and was identified as 15095_BR 2015. These results corroborate previously published data about the spread of the ZIKV Asian lineage that was first reported in the outbreaks of the Pacific Islands (Musso et al. 2014). To track the introduction of ZIKV in Brazil a retrospective and more extensive analysis of additional 

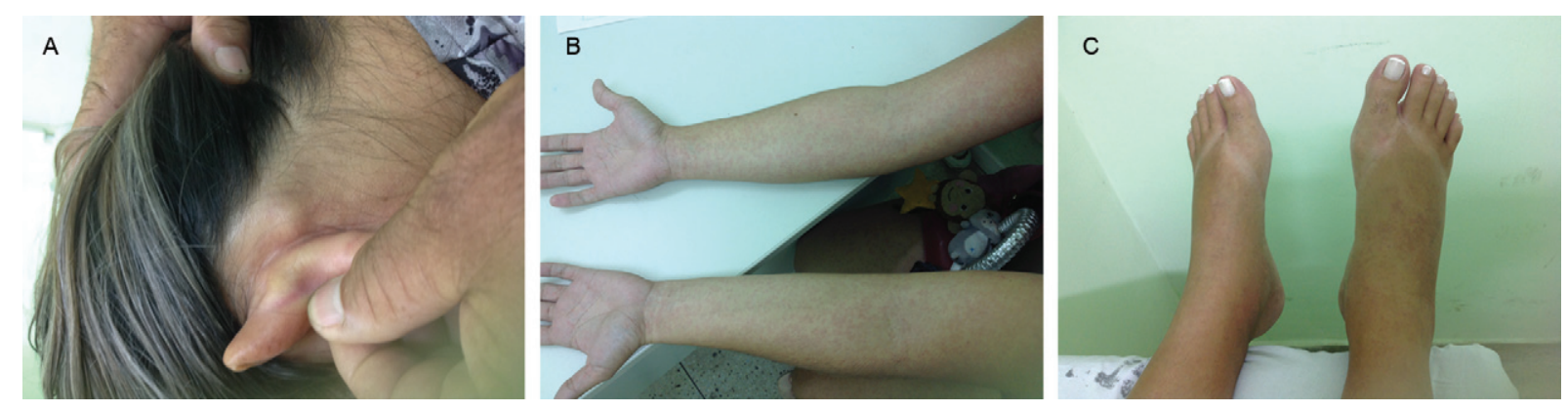

Fig. 3: Zika virus clinical findings in patients from Natal, state of Rio Grande do Norte, Brazil. A: lymphadenopathy; B: maculopapular rash; C: periarticular swelling.

samples from other Brazilian regions is needed, as well as a complete viral genetic characterisation. However, one plausible hypothesis is the arrival of the new emergent virus during the soccer World Cup in 2014.

Seven of the eight patients with confirmed ZIKV disease were female, the median age was 39 years (range, 1865 ), all of them lived in Natal and had relatives with the same symptoms. The most commonly reported symptoms were maculopapular rash (100\%) (Fig. 3) and pain. The pain scale was applied for six of them and the pain levels were high in most patients, with levels of zero (1/7), seven $(2 / 7)$, nine $(1 / 7)$ or $10(2 / 7)$. The pain duration ranged from two-15 days, except for one patient who had pain for more than 21 days. Other symptoms included headache (6/8), retroorbital pain (4/8) and myalgia (6/8). Myalgia was not intense. Joint pain was reported for seven patients, including pain in the hands (5), ankle (4), elbow (4), knee and wrist (3) and foot (2); one patient reported cervical pain.

During the clinical examination, all the patients were haemodynamically normal and periarticular swelling (Fig. 3) was present in six of them, with predominance in the hands $(50 \%)$. Fever was reported in six patients, but high fever (around $39^{\circ} \mathrm{C}$ ) in only two. The duration of fever ranged from one-eight days. Submandibular or cervical lymphadenopathy (Fig. 3) occurred in three patients. No purulent conjunctivitis was observed. ZIKV can produce a clinical relevant disease, which lasts for approximately two weeks. The patients observed in Natal had intense pain resembling CHIKV infection, but the clinical course was shorter. To date, no death or complications were associated with ZIKV illness in Natal.

The blood cell count revealed that only two patients had leukopaenia, the others had normal levels of leukocytes and neutrophils and platelets were normal in all of them. The tourniquet tests were negative in seven of the patients.

We report here the first identification of ZIKV as the causative agent of an outbreak in the northeastern Brazil. It represents the first autochthonous transmission of ZIKV in the country. Although most of the patients had mild illness, clinicians and public health officials should be aware of the risk of expansion of this new emerging virus, especially given the naïve immunological status of the Brazilian population. Spreading of the disease in the country might occur by virtue of the large population mobility and the widespread occurrence of the transmit- ting vectors. Furthermore the complex epidemiological context with the co-circulation of DENV, CHIKV and ZIKV cannot be neglected. DENV and ZIKV (DupontRouzeyrol et al. 2015) or DENV and CHIKV (Caron et al. 2012) co-infections have already been reported.

The effect of the concurrent outbreaks caused by these three different arboviruses is unknown. ZIKV disease was associated with neurological and autoimmune complications in a context of concurrent circulation with DENV in French Polynesia (Roth et al. 2014). DENV also circulates in Natal. Further studies are needed to unveil whether co-infection and subsequent infection by different arboviruses can affect the course of the disease, the occurrence of severe cases and the ways of transmission (vertical, perinatal, sexual) (Foy et al. 2011, Besnard et al. 2014, Musso et al. 2015). Of interest, recent paper by Gourinat et al. (2015) shows evidence of virus secretion in urine for more than 10 days after onset of disease.

The correct clinical and laboratorial differential diagnosis between acute ZIKV, CHIKV and DENV infection will contribute to the patients' prognosis and to drive surveillance actions.

\section{ACKNOWLEDGEMENTS}

To the Sequencing Platform of the Department of Biochemistry and Molecular Biology of the Federal University of Paraná, for viral genomic sequencing, to Dr Helisson Faoro, for discussion, and to Dra Andreia Suzukawa, for technical assistance.

\section{REFERENCES}

Besnard M, Lastère S, Teissier A, Cao-Lormeau VM, Musso D 2014. Evidence of perinatal transmission of Zika virus, French Polynesia, December 2013 and February 2014. Euro Surveill 19: 20751.

Cao-Lormeau VM, Roche C, Teissier A, Robin E, Berry AL, Mallet HP, Sall AA, Musso D 2014. Zika virus, French Polynesia, South Pacific, 2013. Emerg Infect Dis 20: 1084-1086.

Caron M, Paupy C, Grard G, Becquart P, Mombo I, Nso BB, Kassa Kassa F, Nkoghe D, Leroy EM 2012. Recent introduction and rapid dissemination of Chikungunya virus and dengue virus serotype 2 associated with human and mosquito co-infections in Gabon, Central Africa. Clin Infect Dis 55: e45-53.

Dick GWA, Kitchen SF, Haddow AJ 1952. Zika virus. I. Isolations and serological specificity. Trans R Soc Trop Med Hyg 46: 509-520.

Duffy MR, Chen TH, Hancock WT, Powers AM, Kool JL, Lanciotti RS, Pretrick M, Marfel M, Holzbauer S, Dubray C, Guillaumot L, Griggs A, Bel M, Lambert AJ, Laven J, Kosoy O, Panella A, Biggerstaff BJ, 
Fischer M, Hayes EB 2009. Zika virus outbreak on Yap Island, Federated States of Micronesia. N Engl J Med 360: 2536-2543.

Dupont-Rouzeyrol M, O’Connor O, Calvez E, Daures M, John M, Grangeon JP, Gourinat AC 2015. Co-infection with Zika and dengue viruses in 2 patients, New Caledonia, 2014. Emerg Infect Dis 21: 381-382.

Faye O, Faye O, Dupressoir A, Weidmann M, Ndiaye M, Sall AA 2008. One-step RT-PCR for detection of Zika virus. J Clin Virol 43: 96-101.

Faye O, Freire CC, Iamarino A, Faye O, Oliveira JVC, Diallo M, Zanotto PMA, Sall AA 2014. Molecular evolution of Zika virus during its emergence in the 20th century. PLOS Negl Trop Dis 8: e2636.

Foy BD, Kobylinski KC, Foy JLC, Blitvich BJ, da Rosa AT, Haddow AD, Lanciotti RS, Tesh RB 2011. Probable non-vector-borne transmission of Zika virus, Colorado, USA. Emerg Infect Dis 14: 880-882.

Gourinat AC, O'Connor O, Calvez E, Goarant C, Dupont-Rouzeyrol M 2015. Detection of Zika virus in urine. Emerg Infect Dis 21: 84-86.

Ioos S, Mallet HP, Goffart IL, Gauthier V, Cardoso T, Herida M 2014. Current Zika virus epidemiology and recent epidemics. Med Mal Infect 44: 302-307.
Lanciotti RS, Calisher CH, Gubler DJ, Chang GJ, Vorndam V 1992. Rapid detection and typing of dengue viruses from clinical samples by using reverse transcriptase-polymerase chain reaction. $J$ Clin Microbiol 30: 545-551.

Lanciotti RS, Kosoy OL, Laven JJ, Panella AJ, Velez JO, Lambert AJ, Campbell GL 2007. Chikungunya virus in US travelers returning from India, 2006. Emerg Infect Dis 13: 764-767.

Musso D, Nilles EJ, Cao-Lormeau VM 2014. Rapid spread of emerging Zika virus in the Pacific area. Clin Microbiol Infect 20: 595-596.

Musso D, Roche C, Robin E, Nhan T, Teisser A, Cao-Lormeau VM 2015. Potential sexual transmission of Zika virus. Emerg Infect Dis 21: 359-361.

Pierson TC, Diamond MS 2013. Flaviviruses. In DM Knipe, PM Howley (eds.), Fields virology, 6th ed., Lippincott Williams \& Wilkins, Philadelphia, p. 747-794.

Roth A, Mercier A, Lepers C, Hoy D, Duituturaga S, Benyon E, Guillaumot L, Souares Y 2014. Concurrent outbreaks of dengue, Chikungunya and Zika virus infections - an unprecedented epidemic wave of mosquito-borne viruses in the Pacific 2012-2014. Euro Surveill 19: 20929 